\title{
Effect and mechanism of fuzhisan and donepezil on the sirtuin 1 pathway and amyloid precursor protein metabolism in PC12 cells
}

\author{
PENG GUO $^{1-3}$, DESHENG WANG ${ }^{1}$, XIAOMIN WANG ${ }^{2}$, HONGLIN FENG $^{1}$, YING TANG $^{1}$, RUIHONG SUN $^{1}$, \\ YAN ZHENG $^{2}$, LIN DONG ${ }^{2}$, JIAYING ZHAO ${ }^{1}$, XIN ZHANG $^{1}$, SHUYU WANG $^{1}$ and HONGXU SUN ${ }^{1}$ \\ ${ }^{1}$ Department of Neurology, The First Affiliated Hospital, Harbin Medical University, Harbin, Heilongjiang 150001; \\ ${ }^{2}$ Beijing Institute for Brain Disorders, Capital Medical University, Beijing 100069; ${ }^{3}$ Department of Geriatrics, \\ Beijing Tiantan Hospital, Capital Medical University, Beijing 100050, P.R. China
}

Received May 2, 2015; Accepted January 8, 2016

DOI: $10.3892 / \mathrm{mmr} .2016 .4957$

\begin{abstract}
The present study aimed to determine the effect and mechanism of fuzhisan (FZS) and donepezil on the SIRT1 signaling pathway and the metabolism of the amyloid precursor protein (APP) in PC12 cells. An experimental cell model of PC12 cells with A $\beta 25-35$-induced neurotoxicity was established and cell proliferation was determined by the MTT assay following treatment with donepezil and FZS. In addition, cell apoptosis was determined using DAPI staining and light microscopy. Furthermore, western blot analysis and ELISA were utilized to evaluate the expression levels of associated APP, A $\beta 40, \mathrm{~A} \beta 42$, sAPP $\alpha$, sAPP $\beta$, ADAM10, sirtuin 1 (SIRT1) and forkhead box O (FoxO) protein. The results indicated that the cell model was successfully established and FZS protected the PC12 cells from the neurotoxic effects of $\mathrm{A} \beta 25-35$, in a similar effect to donepezil, in a dose-dependent manner. The expression of APP remained at the same level during the experimental period. The levels of $A \beta 40, A \beta 42$ and sAPP $\beta$ were downregulated, where as sAPP $\alpha$, ADAM10, SIRT1 and FoxO expression levels were upregulated. In conclusion, FZS treatment attenuated the A $325-35$-induced neurotoxicity in vitro. The neuroprotective mechanism of FZS was determined, including the induction of ADAM10 and SIRT1-FoxO pathway, which participated in the process of neuroprotection. The present study identified the neuroprotective function of FZS, which may protect against A $\beta$-induced toxicity. Therefore, FZS may be used clinically as a beneficial therapeutic drug for the development or progression of Alzheimer's disease.
\end{abstract}

Correspondence to: Professor Desheng Wang, Department of Neurology, The First Affiliated Hospital, Harbin Medical University, 23 Post Street, Harbin, Heilongjiang 150001, P.R. China

E-mail: wangdesharbin@yeah.net

Key words: Alzheimer's disease, fuzhisan, donepezil, APP, SIRT1

\section{Introduction}

Alzheimer's disease (AD) is a degenerative disorder of the nervous system of elderly individuals, and the most common type of dementia (1). AD is predominantly characterized by the progressive loss or decline of cognition and memory function (1). The pathological characteristics of AD include the formation of intracellular neurofibrillary tangles (NFTs) and extracellular neuritic plaques containing amyloid- $\beta$ (A $\beta$ ) peptide (2). The association of NFTs and $A \beta$ is yet to be fully elucidated, however one hypothesis is that $A \beta$ may trigger the hyper-phosphorylation of the tau protein, leading to the impairment of axonal transport and destabilization of microtubules, resulting in neuronal apoptosis (3). Based on the above, it was suggested that the phosphorylation of tau may act as an important process in the pathogenesis of AD.

A previous study identified the dominant mutations in the amyloid precursor protein (APP) gene, which was also discovered in the presenilin 1 gene (PSEN1) and presenilin 2 gene (PSEN2) (4). A $\beta 1-40$ and A $\beta 1-42$ peptides are generated following the sequential cleavage of APP. A $\beta 1-40$ and A $\beta 1-42$ accumulate to form the amyloid plaques, one of the major characteristics of AD $(2,3)$. Previous studies investigated the role of APP in AD and suggested various hypotheses, however its function remains elusive $(5,6)$. In addition, the mechanisms of activation of the pathways involved in the process of APP, in normal and AD-ageing remain to be fully clarified. A previous study on APP identified that APP was modulated by phosphorylation and phosphorylation-dependent pathways, directly and indirectly (7). Kojro and Fahrenholz (8) reported that the processing of APP occurs via two alternative pathways, the amyloidogenic and nonamyloidogenic pathways, which serve a role in the activation of $\beta$-secretase and $\alpha$-secretase, respectively.

Sirtuins (SIRTs) or silent information regulators were firstly discovered and extracted in yeast (9). SIRT are grouped as class III histone deacetylases, that function by removing acetyl groups from lysines through consumption of nicotinamide adenine dinucleotide (NAD) (9). There are seven homologs of SIRTs (1-7) in humans displaying various enzymatic activities and functions (10). SIRT1, 2 and 3 have higher deacetylase activities compared with SIRT4, 5 and 6 (11-14). SIRTs are 
located in different cell components, such as the nucleus (SIRT1, SIRT6 and SIRT7), cytoplasm (SIRT2) and mitochondria (SIRT3, SIRT4 and SIRT5) (15). SIRTs are highly conserved $\mathrm{NAD}^{+}$-dependent enzymes that have beneficial effects on certain age-associated diseases $(12,13)$. Numerous studies investigated the effects of SIRTs on AD in numerous mouse models in vivo and cell models in vitro (16-18), concluding that the SIRT1 overexpression displayed a protective effect on the AD phenotype, with SIRT1 being the only SIRT studied in $\mathrm{AD}$ animal or cell models. Thus, a therapeutic strategy for AD was designed based on the SIRT1 activity.

Fuzhisan (FZS) is a Chinese herbal complex prescription, which contains the Scutellaria baicalensis Georgi (Labiatae family), Ginseng root (Araliaceae family), Glycyrrhiza uralensis (Leguminosae family) and Anemone altaica (Araceae family) (19). FZS has been used in the clinical therapy for senile dementia for over fifteen years $(19,20)$. Previous studies indicated that FZS increased the cognitive function of patients with $\mathrm{AD}$ or $\mathrm{AD}$ animal models (21). In addition, other effects or functions of FZS have been identified, including neurotrophic effects, neuroprotective functions. FZS regulates cell apoptosis, therefore, it may prevent the toxicity in SH-SY5Y neuroblastoma cells resulting from A $325-35$ accumulation (22). Shirong et al (23) demonstrated that FZS increased the hippocampal acetylcholine levels and enhanced the spatial learning capability. Furthermore, FZS improved glucose metabolism in the brain, and blood flow in the frontal and temporal lobes of patients with AD. However, the specific effects of FZS on tau phosphorylation remain to be identified. In addition, the potential signaling pathways used or the mechanisms for neurotrophic and neuroprotective properties of FZS are elusive.

Therefore, the present study investigated the effects and mechanism of FZS and donepezil on the SIRT1 pathway and APP metabolism in PC12 cells, to identify whether FZS attenuates the A $325-35$-induced toxicity in the cultured PC12 cells, and the effect underlying the signaling mechanisms.

\section{Materials and methods}

Cell culture. The neuronal cell line PC12 was purchased from the Cell Resource Center of Shanghai Institutes, Academy of Sciences (Shanghai, China). The PC12 cells were cultured and grown as a mono-layer of cells in the Roswell Park Memorial Institute 1640 (RPMI-1640) medium (Gibco; Thermo Fisher Scientific, Inc., Waltham, MA, USA) supplemented with $10 \%$ fetal bovine serum (FBS; Gibco; Thermo Fisher Scientific, Inc.), $60 \mu \mathrm{g} / \mathrm{ml}$ penicillin (Sigma-Aldrich, St. Louis, MO, USA) and $100 \mu \mathrm{g} / \mathrm{ml}$ streptomycin (Sigma-Aldrich) in $5 \% \mathrm{CO}_{2}$ at $37^{\circ} \mathrm{C}$.

FZS preparation. The specimen, extraction methods and the effects of evaluation and analysis of FZS were performed as previously described $(19,20)$. The component of FZS, including the Ginseng root, Anemone altaica, Glycyrrhiza uralensis and Scutellaria baicalensis Georgi, was obtained from the Harbin Pharmaceutical Company (Harbin, China). The four components were mixed in proportions of 2:1:1:1, respectively, and macerated for $40 \mathrm{~min}$ in 8 volumes $(\mathrm{v} / \mathrm{w})$ of distilled water, and then decocted for $1 \mathrm{~h}$. The filtrate was collected and the residue was decocted for another $1 \mathrm{~h}$ with 6 volumes (v/w) of distilled water. The filtrate was pooled and lypholized (crude extract). Finally, the crude extract of FZS was dissolved in water at a final concentration of $0.5 \mathrm{~g} / \mathrm{ml}$ (crude drug), and stored at $-20^{\circ} \mathrm{C}$ for further experimental use.

A $\beta 25-35$ peptide preparation. The synthetic $\mathrm{A} \beta 25-35$ peptide (purity $\geq 97 \%$, high-performance liquid chromatography) solution was prepared as previously described (24). Briefly, the A $325-35$ peptide was dissolved in sterile deionized water at a final concentration of $1.0 \mathrm{mM}$, and then incubated at $37^{\circ} \mathrm{C}$ for 3 days to allow for aggregation.

Neurotoxic cell model establishment. The PC12 cell line was cultured in RPMI-1640, supplemented with $10 \% \mathrm{FBS}$ at $37^{\circ} \mathrm{C}$ in a humidified atmosphere supplemented with $5 \% \mathrm{CO}_{2}$. RPMI-1640 medium was added to the cells for 3 days, and then replaced with new medium for another 3 days. In order to prepare the experiments, cells were seeded into 24-well plates $\left(2 \times 10^{4}\right.$ cells $\left./ \mathrm{cm}^{2}\right)$, and after $24 \mathrm{~h}, \mathrm{~A} \beta 25-35(10,20$ or $40 \mu \mathrm{M})$ was added to the medium. Cells were evaluated and observed under a microscope (CKX-31; Olympus Corporation, Tokyo, Japan) at 24 and $48 \mathrm{~h}$ following A $\beta 25-35$ incubation.

Effect of FZS and donepezil on cultured cells. PC12 cells were seeded in 24-well plates and divided into two groups for A 225-35 treatment as follows: i) Donepezil group, treatment with $20 \mathrm{mM}$ donepezil; ii) FZS group, treatment with $2.5,5,15,45,90,135$ or $270 \mu \mathrm{g} / \mathrm{ml} \mathrm{FZS}$. Cells that were not treated with the therapeutic agents were designated as the control group. Following incubation for 24 or $48 \mathrm{~h}$, cells were cultured, harvested and subjected to the different experiments.

Protective effect of FZS and donepezil on cells treated with $A \beta 25-35$. PC12 cells were seeded in 24-well plates and divided into three groups for $\mathrm{A} \beta 25-35$ treatment as follows: i) $\mathrm{A} \beta 25-35$ injury group, $20 \mathrm{mM} \mathrm{A} \beta 25-35$ treatment; ii) donepezil (Sigma-Aldrich) protection group, $20 \mu \mathrm{M}$ donepezil were added to $1 \mathrm{ml}$ culture medium $2 \mathrm{~h}$ prior to $\mathrm{A} \beta 25-35$ injury; iii) FZS protection group, 2.5, 5, 15, 45, 90, 135 or $270 \mu \mathrm{g} / \mathrm{ml}$ FZS were added to $1 \mathrm{ml}$ culture medium $2 \mathrm{~h}$ prior to $\mathrm{A} \beta 25-35$ injury. Following incubation for 24 or $48 \mathrm{~h}$, cells were cultured, harvested and subjected to the different experiments.

3-(4,5-dimethylthiazol-2-yl)-2,5-diphenyltetrazolium bromide (MTT) assay. PC12 cells were cultured in 96-well plates and treated with $20 \mu \mathrm{M} \mathrm{A} \beta 25-35$, FZS or donepezil for $24 \mathrm{~h}$. MTT ( $5 \mathrm{mg} / \mathrm{ml}$; Sigma-Aldrich) was added into each well and incubated at $37^{\circ} \mathrm{C}$ for $4 \mathrm{~h}$. The MTT reaction was terminated by removing the supernatant and dimethyl sulfoxide (Sigma-Aldrich) was added to dissolve formazan products. Finally, the 24-well plates were assessed at the wavelength of $405 \mathrm{~nm}$ on a 550 Bio-Rad microELISA plate reader (Bio-Rad Laboratories, Inc., Hercules, CA, USA). Each experiment was repeated a minimum of three times.

Detection of apoptosis. Apoptosis was detected according to the alterations in nuclear morphology. The nuclei were 
stained with 4',6-diamidino-2-phenylindole dihydrochloride (DAPI) fluorescent DNA dye (Tiangen Biotech Co., Ltd., Beijing, China). Briefly, PC12 cells were cultured in RPMI-1640 and treated with FZS $(0,5,15,45$ and $90 \mu \mathrm{g} / \mathrm{ml})$ for $24 \mathrm{~h}$. Following treatment with FZS and permeabilization, cells were incubated with $2 \mathrm{mg} / \mathrm{ml}$ DAPI in methanol at $37^{\circ} \mathrm{C}$ for $30 \mathrm{~min}$. A fluorescence microscope (IX70; Olympus Corporation) was used to observe cell apoptosis at 300-500 nm UV excitation.

Microscopy. The morphological alterations of the PC12 cell models were observed using a light microscope (Olympus Corporation). During the experimental period, cell morphology was observed and evaluated under the CKX-31 light microscope at various time points.

Enzyme-linked immunosorbent assay (ELISA). The capture antibody, mouse monoclonal anti-human anti-p-Shc (cat. no. sc-81520; 1:1,000; Santa Cruz Biotechnology, Inc., Dallas, TX, USA), was coated at the final concentration of $2 \mathrm{~g} / \mathrm{ml}$ in the antibody coating buffer solution in 96 -well plates at $4^{\circ} \mathrm{C}$ for $24 \mathrm{~h}$. Following incubation with the antibody, cells were washed 4 times with Tris-buffered saline Tween-20 (TTBS; Tiangen Biotech Co., Ltd.) for $5 \mathrm{~min}$, and then blocked with TBS starting block buffer (Pierce Biotechnology, Inc., Rockford, IL, USA) at room temperature for $1 \mathrm{~h}$. A $\beta 40, \mathrm{~A} \beta 42$, sAPP $\alpha$, sAPP $\beta$, SIRT1, forkhead box O (FoxO) standards and biotinylated 4G8 (reporter antibody, at $0.5 \mathrm{~g} / \mathrm{ml}$ in $20 \%$ Pierce Biotechnology, Inc. SuperBlock; 1:1,000; BioLegend, Inc., San Diego, CA, USA; cat. no. SIG-39240-500) were added to the cells, and incubated at $20^{\circ} \mathrm{C}$ for $2 \mathrm{~h}$. Cells were then washed with TTBS and incubated with streptavidin-horseradish peroxidase (Santa Cruz Biotechnology, Inc.) at $20^{\circ} \mathrm{C}$ for $1 \mathrm{~h}$. Subsequently, the fluorogenic substrate Amplex Ultra Red (Molecular Probes; Thermo Fisher Scientific, Inc.) was added to the cells and incubated in RPMI-1640 for $15 \mathrm{~min}$. The reaction products were quantified and examined using the Tecan Genios Pro plate reader (Tecan Group, Ltd., Männedorf, Switzerland) at the wavelength of $450 \mathrm{~nm}$ excitation and $535 \mathrm{~nm}$ emission.

Western blotting. The PC12 cells were harvested and lysed with the radioimmunoprecipitation assay lysis buffer (Beyotime Institute of Biotechnology, Shanghai, China). Lysates were extracted and protein concentration was determined using the Bicinchoninic Acid Assay kit (Bio-Rad Laboratories, Inc.). Proteins were separated by $15 \%$ sodium dodecyl sulfate-polyacrylamide gel electrophoresis and transferred onto nitrocellulose membranes. Following blocking with 5\% non-fat milk in phosphate-buffered saline and Tween 20 (PBST; pH 7.6) at $4^{\circ} \mathrm{C}$ overnight, the membranes were incubated with polyclonal rabbit anti-human SIRT1 (1:1,000; cat. no. sc-15404), polyclonal mouse anti-human APP (1:2,000; cat. no. sc-117075), goat polyclonal anti-human $\mathrm{A} \beta 40$ (1:1,000; cat. no. sc-7496), rabbit polyclonal anti-human A $\beta 42$ (1:1,000; sc-134426), monoclonal mouse anti-human against $\mathrm{APP} \alpha$ and anti-sAPP $\beta(1: 1,000$; cat. no. sc-69796), rabbit polyclonal anti-human A disintegrin and metalloproteinase domain-containing protein (ADAM) 10 $(1: 1,000$; cat. no. sc-25578) and anti-FoxO polyclonal antibodies (1:1,000; Abcam, Cambridge, MA, USA; cat. no. ab195977). All the antibodies were obtained from Santa Cruz Biotechnology, Inc. and incubated overnight at $4^{\circ} \mathrm{C}$. Subsequently, the membranes were incubated with goat anti-rabbit polyclonal antibody (1:1,000; OriGene Technologies, Inc., Beijing, China) or rabbit anti-goat polyclonal antibody (1:1,000; Abcam; cat. no. ab39594) for $1 \mathrm{~h}$ at room temperature. Finally, the membranes were stained with enhanced chemiluminescence reagent (EMD Millipore, Billerica, MA, USA). Western blot bands were analyzed with the Quantity One software, version 2.0 (Bio-Rad Laboratories, Inc.) to evaluate protein expression.

Statistical analysis. Quantitative and statistical analysis of immuno-blot bands were performed using GraphPad Prism software, version 5.0 (GraphPad Software, Inc., La Jolla, CA, USA). Briefly, the blots images were scanned with Typhoon (Pharmacia; GE Healthcare Life Sciences, Uppsala, Sweden), digitalized and saved as a TIF format. The relative protein expression of each blot was determined. Data are presented as the mean \pm standard deviation of at least three independent experiments. Statistical analysis was performed using the t-test, and the differences among two groups or more were determined using one-way or two-way analysis of variance, respectively. $\mathrm{P}<0.05$ was considered to indicate a statistically significant difference. All experiments were repeated for a minimum of three times.

\section{Results}

Neurotoxic cell model is successfully established following treatment with A $\beta 25-35$. Following A $\beta 25-35$ administration, the cell viability of PC12 cells was evaluated using the MTT assay. The results demonstrated that upon $20 \mu \mathrm{M}$ A $\beta 25-35$ treatment the cell viability was reduced by $\sim 40 \%$ compared with the control group $(\mathrm{P}<0.01$; Fig. 1). The results indicated that the neurotoxic cell model of PC12 cells was successfully established.

FZS and donepezil have a protective effect on PC12 cells. Donepezil $(20 \mathrm{mM})$ and FZS $(90 \mu \mathrm{g} / \mathrm{ml})$ treatments had a protective effect on PC12 cells compared with the control group $(\mathrm{P}<0.01$; Fig. 2). Following an increase in the FZS concentration (135 or $270 \mu \mathrm{g} / \mathrm{ml})$ a toxic effect was observed compared with the control group $(\mathrm{P}<0.01$; Fig. 2).

Protective effect of FZS and donepezil on PC12 cells treated with A $\beta 25-35$. Upon the establishment of the neurotoxic cell model of PC12 cells, donepezil $(20 \mathrm{mM})$ and FZS $(2.5,5,15,45,90,135$ and $270 \mu \mathrm{g} / \mathrm{ml})$ were used to evaluate the protective effect against $A \beta 25-35$-induced neurotoxicity. The results indicated that FZS and donepezil had protective effects on cell models (Fig. 3).

FZS inhibits apoptosis in PC12 cells treated with A $\beta 25-35$. PC12 cells were incubated with A $\beta 25-35(20 \mu \mathrm{M})$ for $24 \mathrm{~h}$ and FZS $(90 \mu \mathrm{g} / \mathrm{ml})$, and the anti-apoptotic effect of FZS was evaluated using DAPI staining (Fig. 4A). Compared with the control group, $90 \mu \mathrm{g} / \mathrm{ml}$ FZS treatment protected the cells from apoptosis $(\mathrm{P}<0.01$; Fig. $4 \mathrm{~B})$ and resulted in observable morphological alterations. The morphological alterations illustrated typical apoptotic characteristics, including 


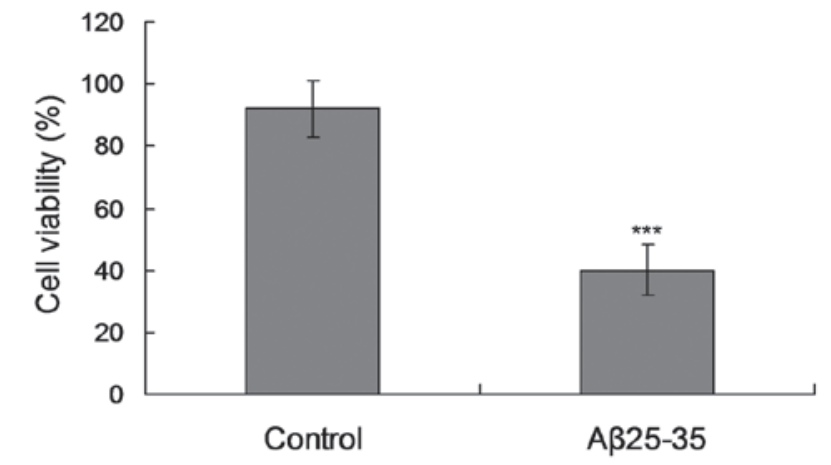

Figure 1. Cell viability of PC12 cells treated with A $\beta 25-35$ peptide $(20 \mu \mathrm{M})$. ${ }^{* * * *} \mathrm{P}<0.001 . \mathrm{A} \beta$, amyloid- $\beta$.

chromatin condensation, DNA fragmentation, apoptotic body formation cell shrinkage and chromatin crescent formation/margination $(21,22)$.

Apoptotic morphology. After a 24-h treatment with $0,5,15,45$ or $90 \mu \mathrm{g} / \mathrm{mlFZS}$, the typical apoptosis morphological changes of cells were observed in the cells (Fig. 5). The alterations included plasmic budding, nuclear chromatin condensation and fragmentation, forming of apoptotic body and phagocytosis of the extruded.

FZS prevents $A \beta 25$-35-induced APP/A $\beta$ processing. Upon verification of the FZS protective effect on PC12 cells, the relevant protein expression levels were determined using western blot and ELISA assays. The results indicated that FZS served a role in the APP/A $\beta$ processing. The $A \beta 40, A \beta 42$ and sAPP $\beta$ levels were downregulated. The level of sAPP $\alpha$ was upregulated in this study (Fig. 6).

FZS promotes the expression of ADAM10 and regulates the SIRT1-FoxO signaling pathway. The observation that ADAM10 levels are markedly increased in PC12 cells treated with FZS (Fig. 7; $\mathrm{P}<0.05$ ). The results suggested that ADAM10 is involved in the basal unstimulated processing of the APP. SIRT1 and FoxO protein expression levels demonstrated an increasing tendency (Fig. 7), indicating that FZS may serve a role in promoting the expression of ADAM10 and regulating the SIRT1-FoxO signaling pathway.

\section{Discussion}

The results of the present study indicated that FZS may prevent A $325-35$-induced neurotoxicity as demonstrated by the increased apoptosis and reduced cell viability. Furthermore, FZS serves an important role in preventing the A $\beta 25$-35-induced APP/A $\beta$ accumulation or processing in the AD model, through promotion of ADAM10 expression and regulation of the SIRT1-FoxO signaling pathway.

In the present study, the cell viability of the PC12 cells was observed to be significantly reduced following treatment with the A $\beta 25-35$ peptide $(20 \mu \mathrm{M})$. The results demonstrated that upon $\mathrm{A} \beta 25-35(20 \mu \mathrm{M})$ treatment, cell viability was reduced to $\sim 40 \%$, indicating successful establishment of the neurotoxic cell model. However, the FZS could prevent the cell neurotoxicity induced by the $A \beta 25-35$ peptide treatment in a concentration-dependent manner. These results were consistent with a previous study which indicated that FZS protected the neuroblastoma cell line SH-SY5Y from the A $\beta$-induced cell apoptosis (20). In addition, another study indicated that FZS protected cortical neurons from $\mathrm{A} \beta$-induced apoptosis (22).

Upon confirmation of the protective effect of FZS on the cell model, relevant protein expression levels were determined using the western blotting and the ELISA assays. The results indicated that FZS had a role in the APP/A $\beta$ processing in AD. Compared with the control group, the expression levels of APP remained stable, where as $\mathrm{A} \beta 40, \mathrm{~A} \beta 42$ and sAPP $\beta$ expression levels were downregulated and SAPP $\alpha$ was upregulated.

APP is an important component of the amyloid cascade and AD (4). APP is processed or cleaved by numerous pathways, including $\alpha, \beta$ or $\gamma$ cleavage forms (4). Among the above cleavage form, the most important physiological route involving cleavage is the cleavage by $\alpha$-secretase along with the secretory pathway, which ranges from Golgi to plasma membrane (4). A previous study demonstrated that the $\alpha$-secretase cleavage mainly appears within the localization of A $\beta$ in APP (4). Furthermore, cleavage of $\alpha$-secretase leads to the secretion of soluble extracellular APP, named sAPP $\alpha$ (6). Although numerous cells possess a basal level of $\alpha$-secretase activity, the proteolysis of APP by the cleavage of $\alpha$-secretase is increased by diverse intracellular pathways, for example, the activation of the protein kinase $\mathrm{C}$ (PKC) (5). The activation or reactivation of other membrane receptors coupled to PKC was indicated to enhance the APP cleavage by $\alpha$-secretase. Furthermore, the experimental findings illustrated that the sAPP $\alpha$ may have a role in the neuroprotective function in the processes of memory and learning capability (6). Therefore, it was hypothesized that the metabolism of APP or its regulation via $\alpha$-secretase pathway may be correlated with the mechanism of AD pathogenesis. Hartmann et al (25) demonstrated that the ADAMs are capable of cleaving the APP in different cell systems, at the $\alpha$-cleavage domains. At present, the most commonly suggested ADAMs for candidate $\alpha$-secretases include ADAM10, ADAM9 and ADAM17 (25). These ADAMs illustrate the identified structures and are all sensitive to the peptide hydroxamates, however, a previous study demonstrated that ADAM17 does not possess inducible $\alpha$-secretase activity (25). Another study indicated that ADAM10 has a PKC-stimulated $\alpha$-secretase activity and other classical characteristics, excluding the APP proteolytic processing (26). Evaluation of the $\alpha$-secretase activity is critical in patients with $\mathrm{AD}$, and may be significant for acknowledging the role of $\alpha$-secretase in AD pathogenesis and progression (27).

The current study demonstrated that the levels of ADAM10 were significantly increased in PC12 cells treated with FZS. In addition, ADAM10 was involved in the basal unstimulated APP processing, and may be involved in the progression of AD (28). In the present study, the reduction or increase of ADAM10 were hypothesized to trigger the $\beta$-secretase amyloidogenic cleavage of APP. This hypothesis was verified by a previous study, which demonstrated that increased sAPP $\alpha$ release and $\alpha$-secretase activity subsequent to reduction of cholesterol in neuronal cell lines may lead to the reductive secretion of $A \beta$ and $\operatorname{sAPP} \beta(29)$. 


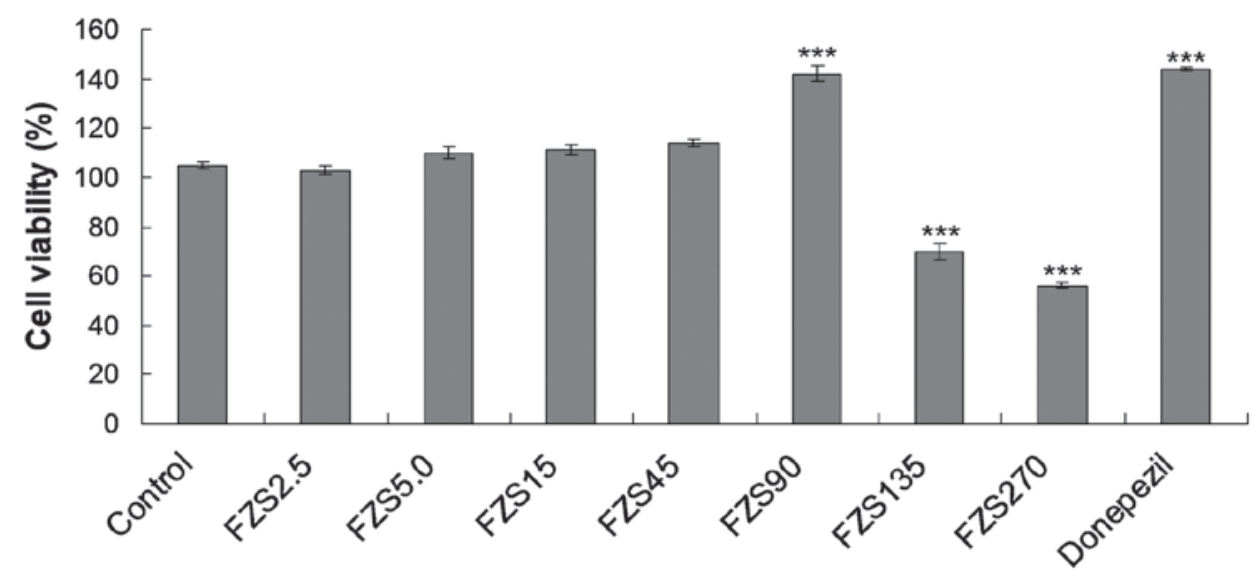

Figure 2. Cell viability of PC12 cells treated with FZS and donepezil. ${ }^{* * *} \mathrm{P}<0.001$, vs. the control group. FZS, fuzhisan.

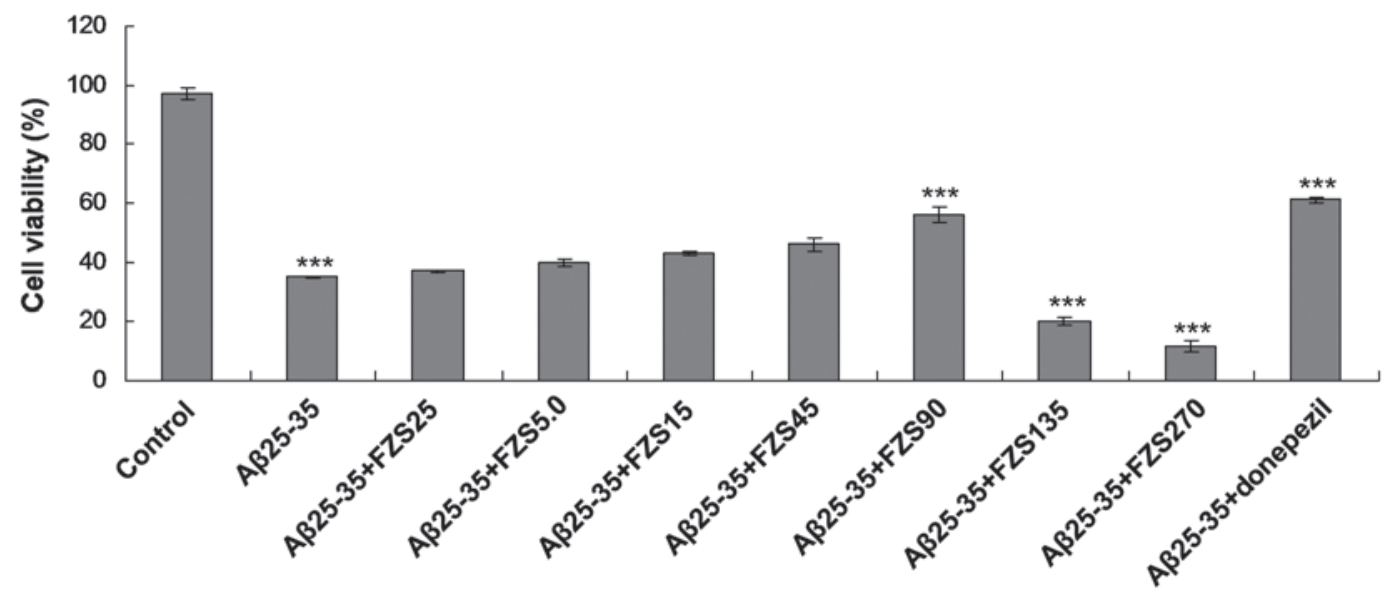

Figure 3. Protective effect of FZS and donepezil on cultured cells treated with A $\beta 25-35 .{ }^{* * * *} \mathrm{P}<0.001$, vs. the control group. FZS, fuzhisan; $A \beta$, amyloid- $\beta$.

$\mathbf{A}$

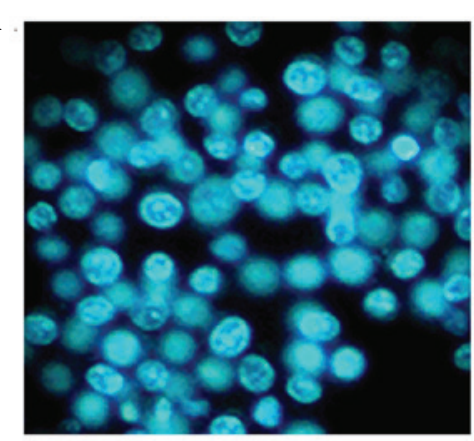

$90 \mu \mathrm{g} / \mathrm{ml} \mathrm{FZS}$

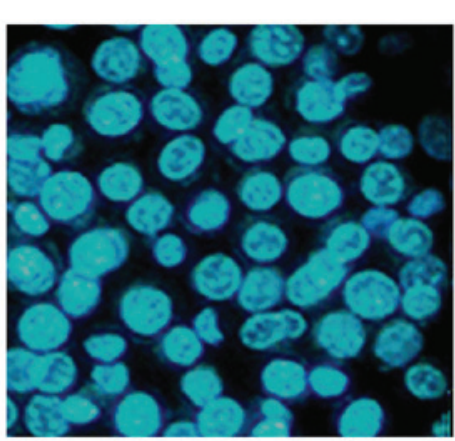

Control
B

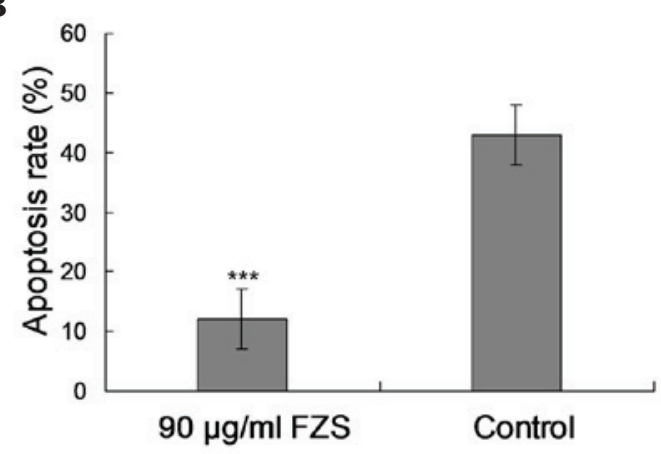

Figure 4.FZS protected against cell apoptosis and led to the demonstrated morphological alterations. Apoptosis was assessed with 4',6-diamidino-2-phenylindole dihydrochloride. The stained PC12 cells were visualized using a fluorescence microscope. (A) Images of the apoptosis examination. (B) Statistical analysis of the apoptotic rate. ${ }^{* * *} \mathrm{P}<0.001$. FZS, fuzhisan.

The precise biochemical mechanism for the sAPP $\alpha$ and $\mathrm{A} \beta$ formation remains unclear, although numerous studies have indicated the abnormal formations of these two parameters in patients with AD (30). The production or release of APP from platelets is associated with two critical intracellular signaling pathways, the PKC activation pathway and the cyclooxygenase pathway. Multiple intracellular signaling pathways may have an effect on the reduced thrombin-induced $\alpha$ APP release in patients with AD (31). Therefore, the current study suggested that the reduced ADAM10 levels and the modified intracellular cascade may regulate the processing and trafficking of APP.

Patel et al (32) identified the protective effect of SIRT1 on $\mathrm{AD}$, and demonstrated that calorie restriction reduced the $\mathrm{A} \beta$ levels and plaque formation in transgenic AD mouse brains. In addition, a reduction in $A \beta$ has been demonstrated in the cortex of starved squirrel monkeys, and is inversely correlated 


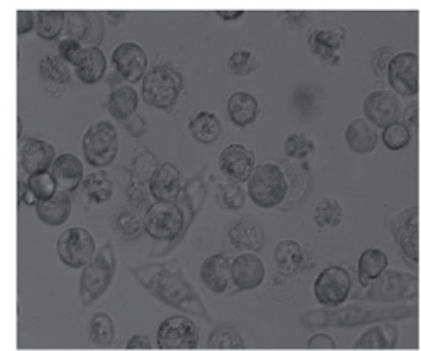

$0 \mu \mathrm{g} / \mathrm{ml} \mathrm{FZS}$

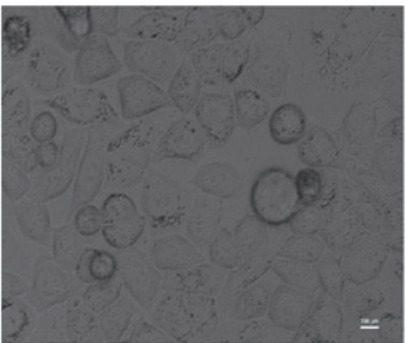

$15 \mu \mathrm{g} / \mathrm{ml} \mathrm{FZS}$

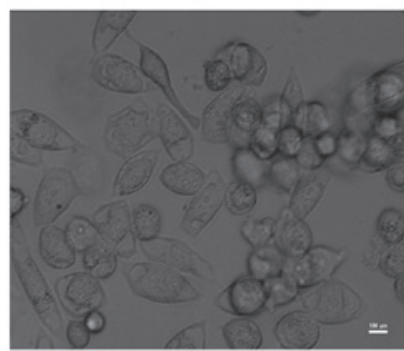

$5 \mu \mathrm{g} / \mathrm{ml} \mathrm{FZS}$

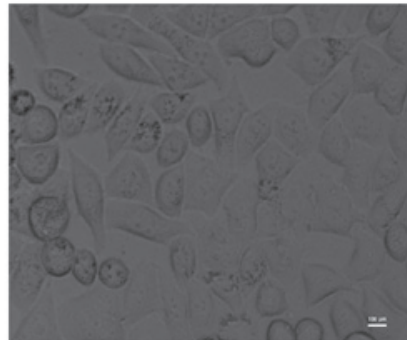

$90 \mu \mathrm{g} / \mathrm{ml} \mathrm{FZS}$

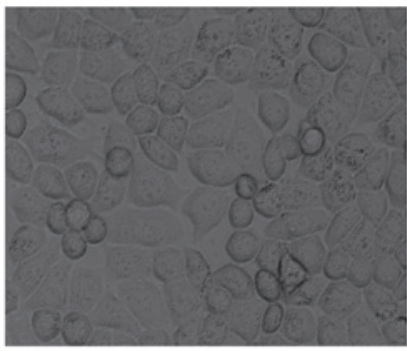

$15 \mu \mathrm{g} / \mathrm{ml}$ FZS

Figure 5. Morphology of the cell apoptosis under the light microscope (magnification, $\mathrm{x} 400$ ). Upon treatment with FZS for 24 h, the cell morphology indicated plasmic budding, nuclear chromatin condensation and fragmentation and phagocytosis of extruded and apoptotic bodies. FZS, fuzhisan.

A

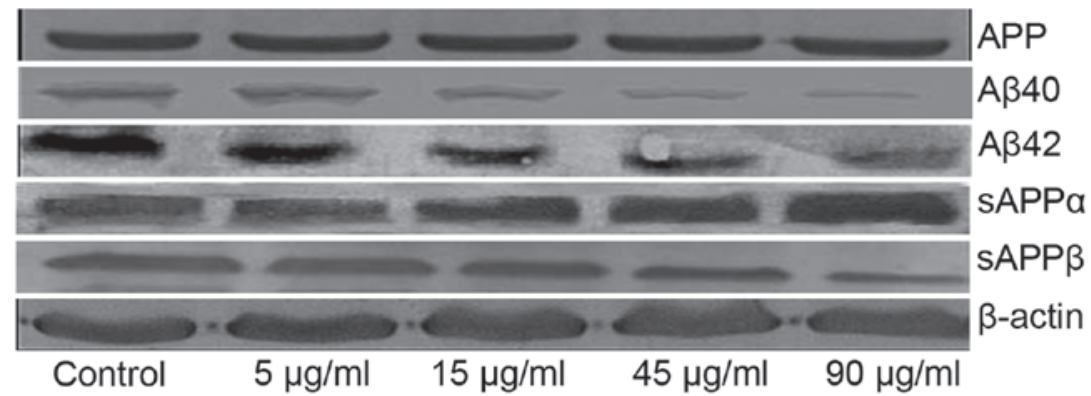

B
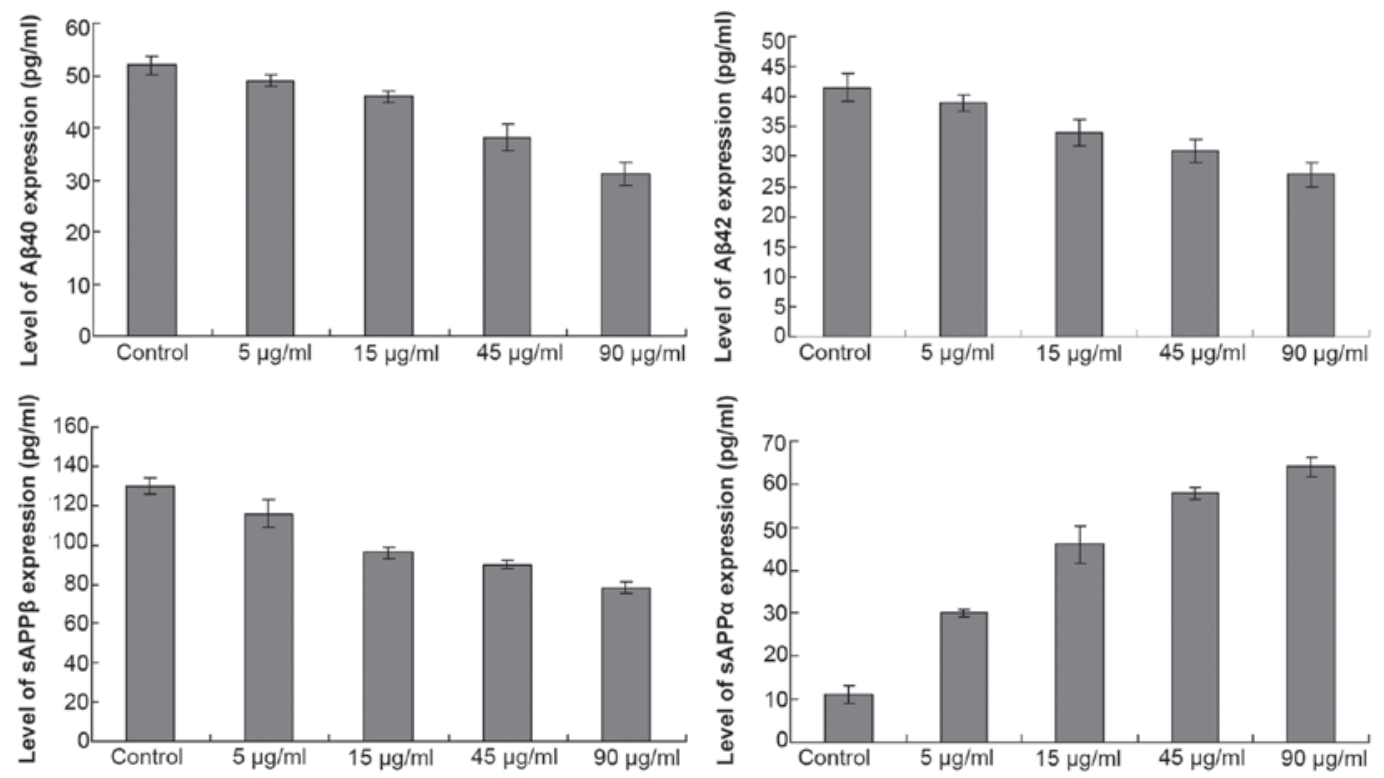

Figure 6. FZS prevents A $\beta 25-35$-induced APP/A $\beta$ processing. PC12 cells were treated with FZS (5, 15, 45 or $90 \mu \mathrm{g} / \mathrm{ml})$ for 24 h. (A) Protein expression levels of APP, A $\beta 40, A \beta 42$, sAPP $\alpha$ and sAPP $\beta$. $\beta$-actin served as a loading control. (B) Enzyme-linked immunosorbent assay analysis on APP, A $\beta 40, A \beta 42$, sAPP $\alpha$, and sAPP $\beta$ in the supernatant of nutrient solution. FZS, fuzhisan; A $\beta$, amyloid $\beta$; APP, amyloid precursor protein; sAPP $\alpha$, soluble APP $\alpha$ peptide.

with SIRT1 (32). The above studies suggest that SIRT1 has a neuroprotective effect on AD progression. Furthermore, previous studies demonstrated that SIRT1 activation reduced brain atrophy and neuronal apoptosis induced by the 
A

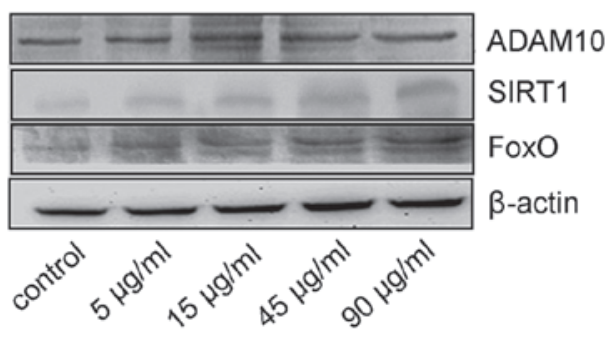

C

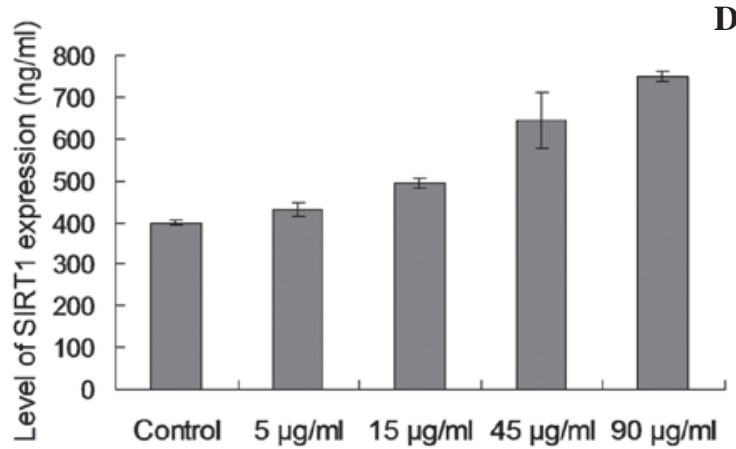

B

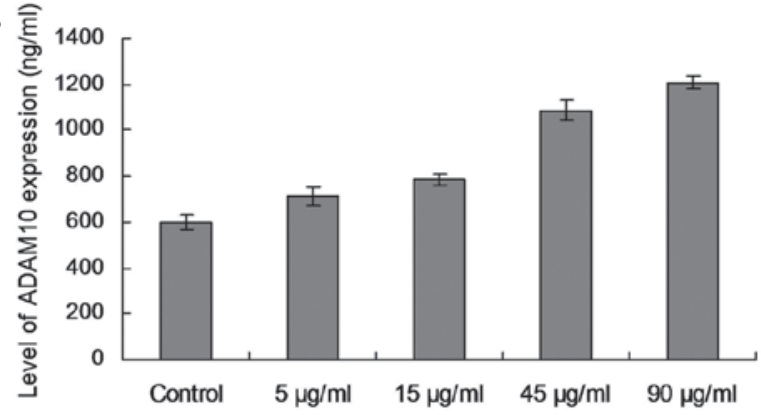

Figure 7. FZS promotes the expression of ADAM10 and regulates the SIRT1-FoxO signaling pathway. PC12 cells were treated with FZS $(5,15,45 \mathrm{or} 90 \mu \mathrm{g} / \mathrm{ml})$ for $24 \mathrm{~h}$. (A) Protein expression levels of ADAM10, SIRT1 and FoxO. $\beta$-actin serves as the loading control. Enzyme-linked immunosorbent assay analysis was conducted on (B) ADAM10, (C) SIRT1 and (D) FoxO in the supernatant of nutrient solution. FZS, fuzhisan; ADAM, A disintegrin and metalloproteinase domain-containing protein; SIRT1, situin 1; FoxO, forkhead box O.

progression of AD $(33,34)$. SIRT1 deficiency was associated with the enhanced phosphorylated-tau levels in neurons and the number of NFTs in the AD brain $(32,33)$.

The SIRT1 molecule primarily targets the two AD pathological biomarkers, tau protein and $\mathrm{A} \beta$ peptide. The phosphorylated tau degradation reduces the neuronal apoptosis and improves the cognitive function in $\mathrm{AD}$ mice. However, the tau breakdown is suppressed upon acetylation of the tau protein by the histone acetyltransferase p300. During the process, SIRT1 deacetylates the acetylated tau, and subsequently decreases the tau levels. Furthermore, SIRT1 inhibition may result in the opposite effect, increasing the tau levels and exacerbating the accumulation of the phosphorylated-tau (35).

Furthermore, previous studies indicated that resveratrol administration and overexpression of SIRT1 may reduce the $\mathrm{A} \beta$ levels in vitro and in vivo (9,32-34). The $\mathrm{A} \beta$ peptide is generated from APP, a physiological protein, and overexpression of SIRT1 stimulates the $\alpha$-secretase production in neurons and mice models $(32,34)$. SIRT1 regulation has an effect on activation of the retinoic acid receptor pathway and inhibition of the rho-associated, coiled-coil-containing protein kinase 1 (10). Furthermore, SIRT1 inhibits the NF-kB signaling transduction pathway and reduces the $A \beta$ peptide levels (11). The above observations indicated that SIRT1 may be a protective biomarker of $\mathrm{AD}$ progression through multiple pathways and mechanisms, including the degradation of tau protein and the decrease of $\mathrm{A} \beta$ peptide levels. In the current study, SIRT1 and FoxO levels demonstrated an increasing tendency, indicating that FZS has a role in the regulation of the SIRT1-FoxO signaling pathway.

SIRT1 is used to determine the association between the aging-associated signaling cascades $(9,32)$. Furthermore,
SIRT1 is a selective activator of the FoxO signaling pathway, and acts as a selective inhibitor of the NF- $\mathrm{BB}$ signaling pathway (36). SIRT1 increases the FoxO-dependent longevity functions, however, it inhibits the NF- $\mathrm{BB}$-dependent processes of inflammation in aging (9,34). Brunet et al (37) demonstrated that the FoxO/Daf-16 and SIRT/Sir2 longevity genes share certain similar functions in C. elegans and human mammalian system. For example, the interaction between the FoxOs and the SIRT1 enhanced the effects against the oxidative stress and increased the cell-cycle arrest (37). A previous study indicated that the SIRTs affect the FoxO-dependent longevity via another mechanism. For example, SIRT1 increases the efficiency of the nuclear translocation and the trapping of FoxO1, which may enhance the targeted gene-specific transcription (38).

The components of FZS that promote the neuron-protective functions remain to be elucidated (39). Ginseng, an important component of FZS, was demonstrated to alleviate numerous ailments, particularly those in patients associated with increased age and memory deterioration (40). A previous study demonstrated that the ginsenoside Rb1 blocked the A $325-35$ peptide-induced tau phosphorylation via inhibition of the Cdk5 activity (40). Thus, ginseng may inhibit the A $\beta$-induced neurotoxicity. Other components of FZS, such as anemone altaica, scutellaria baicalensis and glycyrrhiza uralensis, will need further investigation as they may contribute to the its function.

In conclusion, FZS inhibits the A $\beta 25-35$-induced neurotoxicity. Induction of ADAM10 and SIRT1-FoxO pathway may serve a role in the neuroprotective effects of FZS and its pathogenic mechanism. The results of the present study demonstrated novel insights into the neuroprotective function 
of FZS against A $\beta$-triggered neurotoxicity. Furthermore, FZS may act as a therapeutic drug for the AD progression and pathology.

\section{References}

1. Xing S, Shen D, Chen C, Wang J and Yu Z: Early induction of oxidative stress in a mouse model of Alzheimer's disease with heme oxygenase activity. Mol Med Rep 10: 599-604, 2014.

2. Ferri CP, Prince M, Brayne C, Brodaty H, Fratiglioni L, Ganguli M, Hall K, Hasegawa K, Hendrie H, Huang Y, et al; Alzheimer's Disease International: Global prevalence of dementia: A Delphi consensus study. Lancet 366: 2112-2117, 2005.

3. Walsh DM and Selkoe DJ: Deciphering the molecular basis of memory failure in Alzheimer's disease. Neuron 44: 181-193, 2004.

4. Hardy J and Selkoe DJ: The amyloid hypothesis of Alzheimer's disease: Progress and problems on the road to therapeutics. Science 297: 353-356, 2002.

5. Tanzi RE and Bertram L: Twenty years of the Alzheimer's disease amyloid hypothesis: A genetic perspective. Cell 120 $545-555,2005$.

6. Postina R, Schroeder A, Dewachter I, Bohl J, Schmitt U, Kojro E, Prinzen C, Endres K, Hiemke C, Blessing M, et al: A disintegrin-metalloproteinase prevents amyloid plaque formation and hippocampal defects in an Alzheimer's disease mouse model. J Clin Invest 113: 1456-1464, 2004.

7. De Strooper B: Loss-of-function presenilin mutations in Alzheimer disease. Talking Point on the role of presenilin mutations in Alzheimer disease. EMBO Rep 8: 141-146, 2007.

8. Kojro E and Fahrenholz F: The non-amyloidogenic pathway: Structure and function of $\alpha$-secretases. Subcell Biochem 38: 105-127, 2005.

9. Sinclair DA and Guarente L: Extrachromosomal rDNA circles - a cause of aging in yeast. Cell 91: 1033-1042, 1997.

10. Chen J, Zhou Y, Mueller-Steiner S, Chen LF, Kwon H, Yi S, Mucke L and Gan L: SIRT1 protects against microglia-dependent amyloid-beta toxicity through inhibiting NF-kappaB signaling. J Biol Chem 280: 40364-40374, 2005.

11. Qin W, Yang T, Ho L, Zhao Z, Wang J, Chen L, Zhao W, Thiyagarajan M, MacGrogan D, Rodgers JT, et al: Neurona SIRT1 activation as a novel mechanism underlying the prevention of Alzheimer disease amyloid neuropathology by calorie restriction. J Biol Chem 281: 21745-21754, 2006.

12. Kim D, Nguyen MD, Dobbin MM, Fischer A, Sananbenesi F, Rodgers JT, Delalle I, Baur JA, Sui G, Armour SM, et al: SIRT1 deacetylase protects against neurodegeneration in models for Alzheimer's disease and amyotrophic lateral sclerosis. EMBO J 26: 3169-3179, 2007.

13. Julien C, Tremblay C, Emond V, Lebbadi M, Salem N Jr, Bennett DA and Calon F: Sirtuin 1 reduction parallels the accumulation of tau in Alzheimer disease. J Neuropathol Exp Neurol 68: 48-58, 2009.

14. Donmez G and Guarente L: Aging and disease: Connections to sirtuins. Aging Cell 9: 285-290, 2010.

15. Min SW, Cho SH, Zhou Y, Schroeder S, Haroutunian V, Seeley WW, Huang EJ, Shen Y, Masliah E, Mukherjee C, et al: Acetylation of tau inhibits its degradation and contributes to tauopathy. Neuron 67: 953-966, 2010.

16. Donmez G: The neurobiology of sirtuins and their role in neurodegeneration. Trends Pharmacol Sci 33: 494-501, 2012.

17. Donmez G, Wang D, Cohen DE and Guarente L: SIRT1 suppresses beta-amyloid production by activating the alpha-secretase gene ADAM10. Cell 142: 320-332, 2010.

18. Haigis MC and Sinclair DA: Mammalian sirtuins: Biological insights and disease relevance. Annu Rev Pathol 5: 253-295, 2010.

19. Li XL, Wang S, Zhao BQ, Li Q, Qu HY, Zhang T, Zhou JP and Sun MJ: Effects of Chinese herbal medicine fuzhisan on aged rats. Exp Gerontol 43: 853-858, 2008.
20. Zhao J, Wang D, Duan S, Wang J, Bai J and Li W: Analysis of fuzhisan and quantitation of baicalin and ginsenoside $\mathrm{Rb}(1)$ by HPLC-DAD-ELSD. Arch Pharm Res 32: 989-996, 2009.

21. Gang BZ and Wang CL: The efficacy of Fuzhisan in patients with Alzheimer's disease. Chin J Apoplexy Nerv Dis 22: 527-529, 2005.

22. Wen SR, Wang DS and Zhang JY: Effect of Fuzhisan on the area of neurosome and the length of axon. Chin J Clin Rehabil 9: 241-243, 2005

23. Shirong W, Desheng W and Jingyan Z: The effect of FZS on the cellular function of SH-SY5Y. J Harbin Med Univ 37: 383-388, 2003.

24. Sul D, Kim HS, Lee D, Joo SS, Hwang KW and Park SY: Protective effect of caffeic acid against beta-amyloid-induced neurotoxicity by the inhibition of calcium influx and tau phosphorylation. Life Sci 84: 257-262, 2009.

25. Hartmann D, Tournoy J, Saftig P, Annaert W and De Strooper B Implication of APP secretases in notch signaling. J Mol Neurosci 17: 171-181, 2001.

26. Vieira SI, Rebelo S and Domingues SC: da Cruz e Silva EF and da Cruz e Silva OA. S655 phosphorylation enhances APP secretory traffic. Mol Cell Biochem 9: 8-17, 2009.

27. Goodman AB: Retinoid receptors, transporters, and metabolizers as therapeutic targets in late onset Alzheimer disease. J Cell Physiol 209: 598-603, 2006.

28. Costa RM, Drew $C$ and Silva AJ: Notch to remember. Trends Neurosci 28: 429-435, 2005.

29. Corcoran JPT, So PL and Maden M: Disruption of the retinoid signalling pathway causes a deposition of amyloid $\beta$ in the adult rat brain. Eur J Neurosci 20: 896-902, 2004.

30. Firestein R, Blander G, Michan S, Oberdoerffer P, Ogino S, Campbell J, Bhimavarapu A, Luikenhuis S, de Cabo R, Fuchs C, et al: The SIRT1 deacetylase suppresses intestinal tumorigenesis and colon cancer growth. PLoS One 3: e2020, 2008

31. Yoon K and Gaiano N: Notch signaling in the mammalian central nervous system: Insights from mouse mutants. Nat Neurosci 8: 709-715, 2005.

32. Patel NV, Gordon MN, Connor KE, Good RA, Engelman RW, Mason J, Morgan DG, Morgan TE and Finch CE: Caloric restriction attenuates Abeta-deposition in Alzheimer transgenic models. Neurobiol Aging 26: 995-1000, 2005.

33. Sydow A, Van der Jeugd A, Zheng F, Ahmed T, Balschun D, Petrova O, Drexler D, Zhou L, Rune G, Mandelkow E, et al: Tau-induced defects in synaptic plasticity, learning, and memory are reversible in transgenic mice after switching off the toxic Tau mutant. J Neurosci 31: 2511-2525, 2011.

34. Santacruz K, Lewis J,Spires T,Paulson J,Kotilinek L, Ingelsson M, Guimaraes A, DeTure M, Ramsden M, McGowan E, et al: Tau suppression in a neurodegenerative mouse model improves memory function. Science 309: 476-481, 2005.

35. Julien C, Tremblay C, Emond V, Lebbadi M, Salem N Jr, Bennett DA and Calon F: Sirtuin 1 reduction parallels the accumulation of tau in Alzheimer disease. J Neuropathol Exp Neurol 68: 48-58, 2009.

36. Frescas D, Valenti L and Accili D: Nuclear trapping of the forkhead transcription factor FoxO1 via Sirt-dependent deacetylation promotes expression of glucogenetic genes. J Biol Chem 280: 20589-20595, 2005.

37. Brunet A, Sweeney LB, Sturgill JF, Chua KF, Greer PL, Lin Y, Tran H, Ross SE, Mostoslavsky R, Cohen HY, et al: Stress-dependent regulation of FOXO transcription factors by the SIRT1 deacetylase. Science 303: 2011-2015, 2004.

38. Giannakou ME and Partridge L: The interaction between FOXO and SIRT1: Tipping the balance towards survival. Trends Cell Biol 14: 408-412, 2004

39. Chen X, Huang T, Zhang J, Song J, Chen L and Zhu Y: Involvement of calpain and 25 of CDK 5 pathway in ginsenoside Rb1's attenuation of beta-amyloid peptide25-35-induced tau hyperphosphorylation in cortical neurons. Brain Res 1200: 99-106, 2008.

40. Lee CH, Kim JM, Kim DH, Park SJ, Liu X, Cai M, Hong JG, Park JH and Ryu JH: Effects of Sun ginseng on memory enhancement and hippocampal neurogenesis. Phytother Res 27: 1293-1299, 2013. 